\title{
The Effect on Ethical Sensitivity of Compassion Level in Nurses
}

\author{
Azime Karakoc Kumsar ${ }^{1}$, Sehrinaz Polat ${ }^{2}$, Feride Taskin Yilmaz ${ }^{3^{*}}$
}

${ }^{1}$ Biruni University, Istanbul, TURKEY

${ }^{2}$ Istanbul University, Istanbul Medical Faculty Nursing Services Directorate, Istanbul, TURKEY

${ }^{3}$ Sivas Cumhuriyet University, Sivas, TURKEY

*Corresponding Author: feride_taskin@ hotmail.com

Citation: Karakoc Kumsar A, Polat S, Taskin Yilmaz F. The Effect on Ethical Sensitivity of Compassion Level in Nurses. Electron J Gen Med. 2021;18(5):em302. https://doi.org/10.29333/ejgm/11011

ARTICLE INFO

Received: 30 Apr. 2021

Accepted: 24 May 2021

\section{ABSTRACT}

Introduction: Nurses should have sufficient knowledge and skills for care, and they are also expected to be able to provide compassionate care and fulfill ethical principles. In fact, a decrease in compassion may lead to a decrease in the importance given to ethical values.

Objectives: The study was conducted to determine the level of compassion and ethical sensitivity of nurses and to identify the relationship between compassion level and ethical sensitivity.

Methods: A cross-sectional study carried out with 689 nurses working in a university hospital in Turkey between January-March 2020. The study data were collected using individual information form, the Compassion Scale, and the Ethical Sensitivity Questionnaire. Mann-Whitney U-test, Kruskal-Wallis test, Spearman's correlation test and multiple linear regression analysis were used to evaluate the data.

Results: It was determined that compassion and ethical sensitivity levels of the nurses were partially high, and that as the compassion levels of nurses increased, the level of ethical sensitivity also increased. Besides, it was determined that the nurses' levels of kindness, common humanity, and mindfulness, which are sub-dimensions of compassion, are factors that significantly affect the ethical sensitivity and that these factors explain $8 \%$ of the total variance at the ethical sensitivity level $\left(R=0.283, R^{2}=0,080, F=9,899, p<0.01\right)$.

Conclusions: It was determined that nurses' compassion and ethical sensitivity levels were partially high, as their level of compassion increased, their ethical sensitivity also increased, and compassion is an important predictor in ethical sensitivity. Practices to increase the compassion level of nurses should be prioritized.

Keywords: compassion, compassion fatigue, ethics, ethical sensitivity, nurse

\section{INTRODUCTION}

Nurses should have sufficient knowledge and skills for care, and they are also expected to be able to provide compassionate care and fulfill ethical principles [1,2]. Having been defined as a superior and virtuous behavior from past to present in almost every culture and religion, compassion is described as the sensitivity of an individual to the situation of another person in distress and the active behavior of him towards the settling of the problems [3]. Compassion that positively affects particularly the physical and psychological health of the individual [4], assists the nursing profession [5]. The patient receiving health care service needs compassion from the nurses for reasons such as disability, helplessness, and insufficiency [6]. Performing nursing care with compassion improves the quality of patient care $[5,7,8]$.

Nurses are at risk of compassion fatigue for reasons such as heavy workload, giving care for fatal cases $[5,9]$, and showing compassion for a long time to individuals who suffers constantly $[10,11]$. Compassion fatigue is described as the physical, emotional, social, and spiritual exhaustion of a nurse that leads to widespread decrease in her desire to empathize and care for others, and her ability and energy $[10,12,13]$. Compassion fatigue is considered as the price of nursing care, and the willingness, ability, and energy of a nurse, who experiences compassion fatigue, for giving care is decreasing day by day [14]. Consequently, nurses may face professional troubles such as abstaining from working with patients, sparing less time for patients, intolerance to patients, failure to be objective, making a medical error, reduced loyalty to the profession, and quitting the job [5,9-12,15].

Since compassion is basically about how people relate to each other, the development of compassion brings along an ethical dimension, which can be as important as the medical and psychological dimensions [4]. Because compassion significantly affects the ability of nurses to give care to patients and their families in accordance with ethical principles. In this context, prevention and management of compassion fatigue is important in terms of solving ethical problems in patient care as well as the health of the nurse [15]. In today's healthcare system where technological advances change almost daily, nurses often confront with ethical problems difficult to settle [7]. In order to solve ethical problems, some ethical principles should be followed and it needs to be determined whether the problem is really an ethical dilemma. Ethical sensitivity is defined as the ability of nurses to distinguish the existing 
ethical problem in order to recognize ethical problems and make the right decisions to solve the problems [16]. Ethical sensitivity is developed through education, maintained with professional competence and by demonstrating behaviors that comply with the ethical codes of the profession [17]. Nurses, who have high ethical sensitivity, recognize the presence of ethical problems much more easily and make the right decisions $[16,18,19]$. In some studies, it was found that the ethical sensitivity levels of nurses were at a medium level $[16,19]$. Today, there is a great need for nurses who are ethically sensitive and able to provide morally acceptable care [18]. In this context, studies that affect the ethical sensitivity of nurses and reveal their development are needed.

Ethical sensitivity is based on empathy and compassion. In this regard, compassion is an important emotion in developing ethical sensitivity [4]. It is emphasized that a sense of compassion should be provided as a basis for ethics in the education of health professionals [20]. It is remarkable that studies in the literature examining nurses' compassion levels and ethical sensibilities are quite limited [1]. Considering the fact that the level of compassion affects the quality of patient care, to increase the number of studies on the subject is important so that the gap in this area can be filled. Evaluation of compassion and ethical sensitivity levels of nurses, who have an important place in the providing of health services in terms of quantity and quality, will make a significant contribution to health professionals and science to prevent compassion fatigue, to protect and apply ethical principles, and to increase the quality of nursing care.

\section{METHODS}

\section{Study Design and Aim}

This cross-sectional study was carried out to determine the level of compassion and ethical sensitivity of nurses and to determine the effect of the level of compassion on ethical sensitivity.

\section{Sample}

This study was conducted between January-March 2020 in a university hospital. The universe of the study consisted of 873 nurses working in the relevant hospital. The sample size was calculated at $95 \%$ confidence interval, with 0.05 deviation, using the sampling method with a known universe $\left[\mathrm{Nt}^{2} \mathrm{pq} / \mathrm{d}^{2}(\mathrm{~N}-\right.$ 1) $\left.+t^{2} p q\right]$, and it was found as 267 . In this context, the sample of the study consisted of 689 nurses selected by simple random sampling method, who worked at the relevant institution at the time of the study and voluntarily accepted to participate in the study. 184 nurses who were not in the institution for reasons such as unpaid leave, maternity leave, and medical report between the specified dates, and who filled the data forms incorrectly and did not agree to participate in the study were excluded from the study. The representation rate of the universe for the study was $78.9 \%$.

\section{Data Collection}

The research data were collected using individual information form, the Compassion Scale, and the Ethical Sensitivity Questionnaire.

Individual information form was prepared by the researchers in line with the literature review consists of 18 questions investigating about the nurses': sociodemographic characteristics (age, gender, marital status, having children, etc.), and professional knowledge (the last completed training program, term of employment as a nurse, shift type, and professional satisfaction, etc.) $[16,18,21]$.

The Turkish validity and reliability of Compassion Scale, which was developed by Pommier [22], was performed by Akdeniz and Deniz [23]. This 5-point Likert-type scale consists of 24 items. The scale has the following six sub-dimensions, each containing 4 items: "kindness, indifference, common humanity, separation, mindfulness, and disengagement". Kindness was conceptualized in terms of being caring toward himself and concerned for others, while it reflects the kindness of nurses for patients. Common humanity means being aware that people are not perfect and can make mistakes. Mindfulness reveals that the individual takes a balanced approach towards his negative emotions. In the subdimensions of indifference, separation, and disengagement, it was expressed how important these sub-dimensions shown by nurses to patients are. The general score of compassion is determined by averaging the subscales and the score is obtained as " 1 " the lowest and " 5 " the highest. When calculating the general score of compassion, sub-dimensions of "indifference, separation, and disengagement" are reversecoded. As the total score from the scale increases, the level of compassion also increases. The Cronbach's Alpha coefficient was found as 0.85 in the study of Akdeniz and Deniz [23]. In our study, we determined the Cronbach's Alpha value as 0.89 .

Ethical Sensitivity Questionnaire, which was developed by Kim Lutzen to measure the ethical sensitivity, was first administered to the physicians and nurses in the psychiatric clinic and then in other units, in the Karolinska Nursing Institute (Sweden-Stockholm) in 1994. The Turkish validity and reliability of the scale was performed by Tosun [24]. This 30item scale consists of the following sub-dimensions: autonomy, benevolence, holistic approach, experiencing conflict, practice, and orientation. The "autonomy" subdimension reflects respecting the autonomy principle and the patient's preferences, while "benevolence" sub-dimension refers to actions to increase the benefit of the patient, "holistic approach" reveals the actions that will both not harm the patient and protect the patient's integrity, "experiencing conflict" sub-dimension means the experience of an internal ethical conflict, "practice" shows deciding action and considering the ethical dimension in practice, and finally "orientation" reflects healthcare professionals' interest in their actions that affect their relationship with the patients. This 7point Likert-type scale is scored between 1 to 7 , whereas " 1 point" indicates the high sensitivity (strongly agree) and "7 points" means low sensitivity (strongly disagree). Low scores indicate high ethical sensitivity, while high scores indicate low sensitivity [18,24]. The Cronbach's Alpha coefficient was found as 0.84 in the study of Tosun [24], while we found it as 0.90 in our study.

Before starting the study, a pre-application was performed with 10 nurses. As a result of the pre-application, no changes were made to the data collection form and the obtained data were included in the research data. The data collection form was distributed to the nurses by visiting the clinic one by one by the researchers, a period of time (10 days) was given to the nurses to fill out individually. The forms were collected by the researchers at the end of this period. 
Table 1. Distribution of Nurses' Individual and Professional Characteristics ( $\mathrm{N}=689$ )

\begin{tabular}{|c|c|c|c|c|c|}
\hline Characteristics & $\mathbf{n}$ & $\%$ & Characteristics & $\mathbf{n}$ & $\%$ \\
\hline Age (year) & & & Working unit & & \\
\hline$<30$ & 236 & 34.3 & Clinic & 389 & 56.5 \\
\hline $31-40$ & 238 & 34.5 & Operating room & 84 & 12.2 \\
\hline $41-50$ & 172 & 25.0 & Intensive care & 96 & 13.9 \\
\hline 51 and over & 43 & 6.2 & Urgent & 83 & 12.0 \\
\hline Gender & & & Polyclinic & 37 & 5.4 \\
\hline Female & 606 & 88.0 & Way of working & & \\
\hline Male & 83 & 12.0 & Continuous day & 292 & 42.4 \\
\hline Marital status & & & Both day and night & 379 & 55.0 \\
\hline Married & 387 & 56.2 & Night constantly & 18 & 2.6 \\
\hline Single & 302 & 43.8 & Weekly working hours & & \\
\hline Education status & & & 40 hours & 502 & 72.9 \\
\hline Health vocational high school & 31 & 4.5 & 41 hours and over & 187 & 27.1 \\
\hline Associate Degree & 52 & 7.5 & Number of patients receiving daily care & & \\
\hline License & 528 & 76.6 & $1-10$ & 342 & 49.6 \\
\hline Postgraduate & 78 & 11.3 & $11-20$ & 177 & 25.7 \\
\hline Working year & & & $21-30$ & 76 & 11.0 \\
\hline $1-10$ & 332 & 48.2 & 31 and over & 94 & 13.6 \\
\hline $11-20$ & 162 & 23.5 & Professional satisfaction & & \\
\hline 21 and over & 195 & 28.3 & Satisfied & 310 & 45.0 \\
\hline Working position in the institution & & & Little satisfied & 283 & 41.1 \\
\hline $\begin{array}{c}\text { State staff } \\
\end{array}$ & 431 & 62.6 & Not glad & 96 & 13.9 \\
\hline Contractual & 258 & 37.4 & Having a professional education about $\mathrm{e}$ & & \\
\hline Choosing the profession willingly & & & Yes & 431 & 62.6 \\
\hline Yes & 479 & 69.5 & No & 95 & 13.8 \\
\hline No & 210 & 3.5 & Does not remember & 163 & 23.7 \\
\hline
\end{tabular}

\section{Data Analysis}

The data obtained from the study were evaluated using the SPSS 22.0 program. The normality of the data was measured with the Kolmogorov-Smirnov test. Since the distribution of the data is not homogeneous; when comparing sociodemographic and professional characteristics with the mean scores of the Compassion Scale and the Ethical Sensitivity Questionnaire, the Mann-Whitney U-test was used for two independent groups, and the Kruskal-Wallis test was used for more than two independent groups. In determining the relationship between the Compassion Scale and the Ethical Sensitivity Questionnaire mean score, Spearman's correlation coefficient was used since the distribution of the data is not homogeneous. Besides, multiple linear regression analysis was used to determine the predictive power of compassion subdimensions on ethical sensitivity. The margin of error was taken as 0.05 .

\section{Ethical Considerations}

Before collecting the data, written consent was obtained from the ethics committee of a university (decision number:2018-07/04) and the institution where the study was conducted. The nurses were informed about the aim, method, and benefits of the study, and they were asked whether they were volunteer to participate in the study and their permission was obtained. As individual rights should be protected in the use of human phenomena in research, the "Informed Consent" condition has been fulfilled in the light of the "Willingness, Volunteering" principle. In addition, written consent was obtained from the relevant authors for the use of the Compassion Scale and the Ethical Sensitivity Questionnaire, which are used as data collection tools.
Table 2. Distribution of Nurses' General and Sub-Dimension Mean Scores Regarding the Compassion Scale and the Ethical Sensitivity Questionnaire

\begin{tabular}{cccc}
\hline Scales & Mean & SD & Range \\
\hline Compassion Scale & & & \\
\hline Kindness & 4.13 & .71 & $1-5$ \\
\hline Indifference & 1.84 & .70 & $1-5$ \\
\hline Common humanity & 3.95 & .71 & $1-5$ \\
\hline Separation & 1.83 & .72 & $1-5$ \\
\hline Mindfulness & 4.05 & .68 & $1-5$ \\
\hline Disengagement & 1.85 & .70 & $1-5$ \\
\hline General & 4.07 & .52 & $1-5$ \\
\hline Ethical Sensitivity Questionnaire & & & \\
\hline Autonomy & 2.89 & .97 & $1-7$ \\
\hline Benevolence & 3.17 & 1.07 & $1-7$ \\
\hline Holistic approach & 2.51 & 1.02 & $1-7$ \\
\hline Experiencing conflict & 4.40 & 1.18 & $1-7$ \\
\hline Practice & 3.20 & 1.08 & $1-7$ \\
\hline Orientation & 2.31 & 1.11 & $1-7$ \\
\hline General & 3.08 & .78 & $1-7$ \\
\hline & & &
\end{tabular}

\section{RESULTS}

Table 1 shows the individual and professional characteristics of nurses.

Table 2 shows the distribution of nurses' general and subdimension mean scores of the Compassion Scale and the Ethical Sensitivity Questionnaire. Accordingly, considering that the highest score that can be obtained from the Compassion Scale is " 5 " and the lowest score is " 1 "; it was determined that nurses' feelings of compassion for others $(4.07 \pm 0.52)$ were above average, they showed compassion the most in kindness $(4.13 \pm 0.71)$ and mindfulness $(4.05 \pm 0.68)$ sub-dimensions while the least in separation $(1.83 \pm 0.72)$ and indifference $(1.84 \pm 0.70)$ 
Table 3. Correlation of Nurses' General and Sub-Dimension Mean Scores Regarding the Compassion Scale and the Ethical Sensitivity Questionnaire

\begin{tabular}{|c|c|c|c|c|c|c|c|}
\hline \multirow[b]{2}{*}{ Compassion Scale } & \multicolumn{6}{|c|}{ Ethical Sensitivity Questionnaire } & \multirow[b]{2}{*}{ Orientation } \\
\hline & General & Autonomy & Benevolence & $\begin{array}{c}\text { Holistic } \\
\text { approach }\end{array}$ & $\begin{array}{l}\text { Experiencing } \\
\text { conflict }\end{array}$ & Practice & \\
\hline Kindness & $-.211^{\star \star}$ & $-.237^{\star \star}$ & $-.120^{\star \star}$ & $-.265^{\star \star}$ & $.172^{\star \star}$ & $-.122^{\star \star}$ & $-.328^{\star \star}$ \\
\hline Indifference & $.160^{\star \star}$ & $.169^{\star \star}$ & $.099^{\star \star}$ & $.230^{\star \star}$ & $-.161^{\star \star}$ & $.091^{\star}$ & $.308^{\star \star}$ \\
\hline Common humanity & $-.180^{\star \star}$ & $-.225^{\star \star}$ & $-.129^{\star \star}$ & $-.289^{\star \star}$ & $.216^{\star \star}$ & -.074 & $-.328^{\star \star}$ \\
\hline Separation & $.099^{\star \star}$ & $.133^{\star \star}$ & .060 & $.180^{\star \star}$ & $-.225^{\star \star}$ & $.088^{\star}$ & $.231^{\star \star}$ \\
\hline Mindfulness & $-.186^{\star \star}$ & $-.239^{\star \star}$ & $-.077^{\star}$ & $-.305^{\star \star}$ & $.225^{\star \star}$ & -.071 & $-.335^{\star \star}$ \\
\hline Disengagement & $.148^{\star \star}$ & $.142^{\star \star}$ & .075 & $.253^{\star \star}$ & $-.133^{\star \star}$ & $.088^{\star}$ & $.298^{\star \star}$ \\
\hline General & $-.206^{\star \star}$ & $-.243^{\star \star}$ & $-.125^{\star \star}$ & $-.321^{\star \star}$ & $.244^{\star \star}$ & $-.118^{\star \star}$ & $-.387^{\star \star}$ \\
\hline
\end{tabular}

Note: Values were determined by Spearman correlation test; ${ }^{\star} p<0.05 ; p<0.01$

Table 4. Multiple regression findings between ethical sensitivity and the Compassion Scale sub-dimensions

\begin{tabular}{|c|c|c|c|c|c|}
\hline Variables & $B$ & $S E$ & $\boldsymbol{B}$ & $t$ & p value \\
\hline Kindness & -.176 & .068 & -.159 & -2.589 & .010 \\
\hline Indifference & -.052 & .066 & -.047 & -.787 & .431 \\
\hline Common humanity & -.120 & .047 & -.113 & -2.567 & .010 \\
\hline Separation & .091 & .065 & .081 & 1.400 & .162 \\
\hline Mindfulness & -.158 & .069 & -.142 & -2.311 & .021 \\
\hline Disengagement & .037 & .065 & .032 & .571 & .568 \\
\hline
\end{tabular}

$R=.283, R^{2}=.080, F=9.899, p=.000$

sub-dimensions. When the nurses' mean score of the Ethical Sensitivity Questionnaire is examined, considering that the score intervals can be taken is 1-7, it was found that the level of ethical sensitivity was partially high $(3.08 \pm 0.78)$. According to the mean score of the sub-dimensions of the Ethical Sensitivity Questionnaire, it was determined that the highest ethical sensitivity was in the orientation sub-dimension (2.31 \pm 1.11 ),

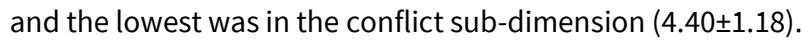

When the relationship between nurses' general mean score of the Compassion Scale and general mean score of the Ethical Sensitivity Questionnaire is examined, it was found that there is a weakly significant negative relationship $(r=-0.206 ; p<0.01)$. In other words, As the mean score of the Compassion Scale increases, the mean score of the Ethical Sensitivity Questionnaire decreases. Accordingly, as the level of compassion of nurses increases, their level of ethical sensitivity also increases. In addition, it was determined that there was also a significant relationship between the general mean score of the Compassion Scale and the mean score of all subdimensions of the Ethical Sensitivity Questionnaire $(p<0.01)$. In the comparison of the mean scores of sub-dimensions of the scales, it was found that there was no relationship only between common humanity and practice; separation and benevolence; mindfulness and practice; disengagement and benevolence $(p>0.05)$ (Table 3$)$.

Table 4 shows the multiple regression analysis results in terms of the predictive power of nurses' compassion subdimensions on ethical sensitivity. Accordingly, it was determined that the nurses' levels of kindness, common humanity, and mindfulness, which are sub-dimensions of compassion, are factors that significantly affect the ethical sensitivity and that these factors explain $8 \%$ of the total variance at the ethical sensitivity level $\left(R=0.283, R^{2}=0.080\right.$, $\mathrm{F}=9.899, \mathrm{p}<0.01$ ). A high level of kindness, common humanity and mindfulness in compassion positively affects the ethical sensitivity of nurses.

Comparing the individual and professional characteristics of the nurses and the Compassion Scale mean scores, it was found that the compassion level of nurses was lower who have the following characteristics: aged under 30 years; male; graduate of vocational school of health; working year of 1-10 years; not choosing the profession willingly; working in the institution under a contract; working 41 hours or more per week; being unsatisfied with their profession $(p<0.05)$. Despite this, it was determined that the number of patients who receive daily care in the unit where the nurses work and the status of having vocational training on ethics is not related to the level of compassion ( $p>0.05$ ).

There was no significant relationship between the mean score of the Ethical Sensitivity Questionnaire and the following characteristics of the nurses: age, gender, year of working, choosing the profession willingly, working position in the institution, weekly working hours, number of patients receiving daily care, having vocational training about ethics ( $p>0.05$ ). On the other hand, it was found that the ethical sensitivity levels of nurses who were graduates of a vocational school of health, work in the operating room, and who were unsatisfied with their profession were lower $(p<0.05)$ (Table 5).

\section{DISCUSSION}

In the study, the compassion and ethical sensitivity levels of nurses were determined and it was shown whether the level of compassion was related to ethical sensitivity.

Compassion, which is a fundamental feeling for human values and ethics [4], is an important value that facilitates the nurse to provide care to the healthy/sick individual [21]. Compassion is a holistic approach model, which is cost-free and speeds up patient recovery [25]. Although it would not be correct to assume that all nurses are compassionate, Ledoux, states that there is a consensus that nurses are compassionate [26].

In the study, it was determined that nurses' feelings of compassion for others were partially high. In their studies carried out with operating room nurses and in their studies conducted with nurses working in different clinics, Çınar and Aslan [25] and Duarte et al. [27], respectively, found that the 
Table 5. Comparison of Nurses' General Mean Scores of Compassion Scale and Ethical Sensitivity Questionnaire by their personal and professional characteristics

\begin{tabular}{|c|c|c|}
\hline \multirow[t]{2}{*}{ Characteristics } & \multirow{2}{*}{$\begin{array}{l}\text { Compassion Scale } \\
\mathrm{M} \pm \mathrm{SD}\end{array}$} & \multirow{2}{*}{$\begin{array}{l}\text { Ethical Sensitivity Questionnaire } \\
\text { M } \pm \text { SD }\end{array}$} \\
\hline & & \\
\hline \multicolumn{3}{|l|}{ Age (year) } \\
\hline$<30$ & $3.93 \pm 0.52$ & $3.08 \pm 0.75$ \\
\hline $31-40$ & $4.09 \pm 0.56$ & $3.14 \pm 0.90$ \\
\hline $41-50$ & $4.20 \pm 0.46$ & $3.05 \pm 0.67$ \\
\hline 51 and over & $4.15 \pm 0.35$ & $2.87 \pm 0.53$ \\
\hline Test & $X^{2}=30.304 ; p=0.000^{\star *}$ & $X^{2}=4.343 ; p=0.227$ \\
\hline \multicolumn{3}{|l|}{ Gender } \\
\hline Female & $4.10 \pm 0.51$ & $3.05 \pm 0.74$ \\
\hline Male & $3.80 \pm 0.57$ & $3.27 \pm 1.02$ \\
\hline Test & $Z=-4.684 ; p=0.000^{\star *}$ & $Z=-1.548 ; p=0.122$ \\
\hline \multicolumn{3}{|l|}{ Education status } \\
\hline $\begin{array}{r}\text { Health vocational high School } \\
\end{array}$ & $3.99 \pm 0.55$ & $3.37 \pm 0.64$ \\
\hline Associate Degree & $4.28 \pm 0.31$ & $2.87 \pm 0.47$ \\
\hline License & $4.05 \pm 0.54$ & $3.09 \pm 0.81$ \\
\hline Postgraduate & $4.08 \pm 0.48$ & $3.05 \pm 0.78$ \\
\hline Test & $x^{2}=8.656 ; p=0.034^{*}$ & $X^{2}=1.476 ; p=0.015^{*}$ \\
\hline \multicolumn{3}{|l|}{ Working year } \\
\hline $1-10$ & $3.96 \pm 0.54$ & $3.10 \pm 0.83$ \\
\hline $11-20$ & $4.14 \pm 0.53$ & $3.14 \pm 0.79$ \\
\hline 21 and over & $4.18 \pm 0.43$ & $3.01 \pm 0.65$ \\
\hline Test & $X^{2}=26.129 ; p=0.000^{\star *}$ & $X^{2}=2.282 ; p=0.319$ \\
\hline \multicolumn{3}{|l|}{ Choosing the profession willingly } \\
\hline Yes & $4.10 \pm 0.50$ & $3.08 \pm 0.79$ \\
\hline No & $3.98 \pm 0.57$ & $3.09 \pm 0.76$ \\
\hline Test & $Z=-2.951 ; p=0.003^{* *}$ & $Z=-0.983 ; p=0.325$ \\
\hline \multicolumn{3}{|l|}{ Working unit } \\
\hline Clinic & $4.06 \pm 0.56$ & $3.01 \pm 0.74$ \\
\hline Operating room & $4.08 \pm 0.44$ & $3.35 \pm 0.78$ \\
\hline Intensive care & $4.05 \pm 0.49$ & $3.03 \pm 0.95$ \\
\hline Urgent & $4.06 \pm 0.53$ & $3.12 \pm 0.68$ \\
\hline Polyclinic & $4.13 \pm 0.41$ & $3.25 \pm 0.79$ \\
\hline $\begin{array}{c}\text { Test } \\
\end{array}$ & $x^{2}=0.794 ; p=0.939$ & $X^{2}=19.194 ; p=0.001^{\star \star}$ \\
\hline \multicolumn{3}{|l|}{ Weekly working hours } \\
\hline 40 hours & $4.14 \pm 0.46$ & $3.04 \pm 0.70$ \\
\hline 41 hours and over & $3.87 \pm 0.62$ & $3.19 \pm 0.96$ \\
\hline Test & $Z=-5.015 ; p=0.000^{\star \star}$ & $Z=-1.419 ; p=0.156$ \\
\hline \multicolumn{3}{|l|}{ Number of patients receiving daily care } \\
\hline $1-10$ & $4.05 \pm 0.52$ & $3.11 \pm 0.78$ \\
\hline $11-20$ & $4.11 \pm 0.51$ & $2.98 \pm 0.74$ \\
\hline $21-30$ & $3.99 \pm 0.51$ & $3.06 \pm 0.72$ \\
\hline 31 and over & $4.08 \pm 0.57$ & $3.19 \pm 0.87$ \\
\hline Test & $X^{2}=4.525 ; p=0.210$ & $X^{2}=4.690 ; p=0.196$ \\
\hline \multicolumn{3}{|l|}{ Professional satisfaction } \\
\hline $\begin{array}{c}\text { Satisfied } \\
\end{array}$ & $4.14 \pm 0.48$ & $3.02 \pm 0.81$ \\
\hline Little satisfied & $4.04 \pm 0.55$ & $3.09 \pm 0.76$ \\
\hline Not glad & $4.00 \pm 0.57$ & $3.27 \pm 0.70$ \\
\hline $\begin{array}{c}\text { Test } \\
\end{array}$ & $X^{2}=10.256 ; p=0.006^{\star \star}$ & $X^{2}=14.713 ; p=0.001^{\star \star}$ \\
\hline \multicolumn{3}{|l|}{ Having a professional education about ethics } \\
\hline Yes & $4.08 \pm 0.51$ & $3.09 \pm 0.80$ \\
\hline No & $3.96 \pm 0.57$ & $3.11 \pm 0.85$ \\
\hline Does not remember & $4.09 \pm 0.53$ & $3.03 \pm 0.67$ \\
\hline Test & $X^{2}=3.035 ; p=0.219$ & $X^{2}=0.667 ; p=0.716$ \\
\hline
\end{tabular}

compassion levels of the nurses were above average. Additionally, in several studies conducted in Turkey and other countries, it was found that the compassion levels of the nurses were at medium levels $[1,28]$. In a meta-analysis study, on the other hand, the prevalence of compassion fatigue in nurses was reported as $47.6 \%$ and it was emphasized that it was high [29]. Other studies have also found that nurses experience high levels of compassion fatigue [29-31]. In the study, the compassion level of nurses to be partially high is considered positive for the quality of nursing care. This finding may be due to the regular in-service training and institutional support that nurses working in the hospital, which is one of the largest university hospitals in Turkey, receive focusing on patient care.

Examining the individual and professional characteristics of the nurses and their compassion levels, it was found that the compassion level of nurses was lower who have the following characteristics: aged under 30 years; male; graduate of vocational school of health; working year of 1-10 years; not 
choosing the profession willingly; working in the institution under a contract; working 41 hours or more per week; being unsatisfied with their profession. When the literature was reviewed, it was found that compassion fatigue increased in nurses at young ages in some studies [8,9], and in nurses aged 40 or older in some other studies [31]; contrary to this study, compassion fatigue was found to be higher in women [21]. Similarly, some studies showed that compassion fatigue levels of nurses with postgraduate education were low [29,31]. In studies examining the relationship between compassion fatigue and year of working, it was reported that nurses working for less than 10 years had a high level of compassion fatigue $[1,28]$.

Although it was determined in the study that there was no difference between the unit worked and the level of compassion, in some studies, it was found that the level of compassion fatigue was higher in nurses working in the following units: primary healthcare [11], emergency [9], and intensive care [28]. In addition, it was determined that the compassion level of nurses with high professional satisfaction was higher [8]. When the studies are examined, it was seen that the findings revealing the relationship between the personal and professional characteristics of nurses and their level of compassion differ. This finding may have resulted from the sample difference and the data collection tool used to evaluate the level of compassion.

Nurses should have high levels of ethical sensitivity in order to recognize ethical problems and make correct decisions [16]. In the study, it was found that the ethical sensitivity levels of nurses were partially high. It was determined in also some other studies that nurses have high ethical sensitivity $[17,18]$. However, in many studies, it was found that the ethical sensitivity levels of nurses were at a medium level [16,19,3237]. It is thought that the ethical sensitivity levels of nurses to be partially high may have resulted from nurses' possibility of encountering more cases with ethical problems in the hospital where the study was conducted.

In the study, it was determined that there is only a relationship between the variables of education, unit of working and professional satisfaction among individual and professional characteristics and levels of ethical sensitivity. Ertuğ et al [33], found that ethical sensitivity was higher in nurses aged over 37 years of age and at the undergraduate level who received ethics training. Kahriman and Calık [18] determined that those who do their profession willingly and who do not receive training in ethics have higher ethical sensitivity. Basak et al [19], found that with increasing age in nurses, ethical sensitivity increased. Besides, in other studies, it was found that the relationship between ethical sensitivity and variables such as age, gender, year of working, and unit of working differed [33-37]. The finding of the study is compatible with the literature and it shows that nurses, especially those with a high level of education and who love their profession, attach more importance to ethical sensitivity in order to increase the quality of care.

In the literature, it has been suggested that compassion fatigue may cause a decrease in the importance given to ethical values [13], and therefore pose a threat in ethical practice [15]. In the study, it was determined that as the level of compassion of nurses increases, the level of ethical sensitivity also increases. In addition, in the multiple regression analysis, it was found that the nurses' levels of kindness, common humanity and mindfulness, which are sub-dimensions of compassion, were an important predictor of ethical sensitivity. In their study, which is the only one on the subject in the literature, Kılıç et al. [1], found that there was no relationship between compassion level and ethical sensitivity. In other studies, it was reported that there was a positive relationship between compassion fatigue and moral distress, and that nurses experiencing compassion fatigue feel moral distress intensely $[38,39]$. The finding of the study may have resulted from the approaches applied in the institution where the study was conducted, focused on improving the quality of patient care and increasing nurse satisfaction. At the same time, this finding reveals that the high level of compassion which nurses show to the patients they give care positively increases their sensitivity in resolving the ethical problems they encounter in the care of these patients.

This study is one of the rare studies examining the relationship between the level of compassion of nurses working in a university hospital in a province in the Marmara region of Turkey and their ethical sensitivity. The fact that the study was carried out in a single institution within a certain time period and the data obtained were based on the selfreports of the nurses participating in the study constituted the limitations of the research. Besides, since the study is limited to a descriptive research style, it remains unclear how changes in the level of compassion differ over the years and whether this change has led to an increase in medical error.

\section{CONCLUSIONS}

In line with the findings obtained, it was determined that nurses' compassion and ethical sensitivity levels were partially high, as their level of compassion increased, their ethical sensitivity also increased, and compassion is an important predictor in ethical sensitivity. This relationship between the level of compassion and ethical sensitivity reveals the priority to increase the level of compassion. In this context, in order to increase the level of compassion of nurses, the following steps are recommended: organizing continuing education programs in subjects such as coping, relaxation, communication skills (particularly using empathy effectively), professional boundaries; providing awareness training on the subject and making screenings; enabling them to allocate more time for themselves; strengthening psychosocial health levels. Additionally, including the concept of compassion and ethical sensitivity in the nursing undergraduate curriculum and teaching prospective nurses compassionate care and ethical sensitivity through examples during their student years may contribute to the adoption and promotion of compassion. However, it is recommended not only to consider qualitative characteristics but also to examine human aspects such as compassion and responsibility while recruiting nurses to the institution. It is recommended to repeat the study, which aims to determine whether changes in the level of compassion of nurses were related to changes in ethical sensitivity, prospectively in different institutions and it is also recommended to conduct the study with a larger sample group.

Author contributions: All authors have sufficiently contributed to the study, and agreed with the results and conclusions.

Funding: No funding source is reported for this study.

Declaration of interest: No conflict of interest is declared by authors. 


\section{REFERENCES}

1. Kılıç D, Bakan AB, Aslan G, Uçar F. The relationship between ethical sensitivity and compassion fatigue in nurses who working in oncology units and intensive care units. Journal of Adnan Menderes University Health Sciences Faculty, 2020;4(1):20-9. https://doi.org/10.46237/amusbfd.745083

2. Çingöl N, Çelebi E, Zengin S, Karakaş M. The investigation of compassion level of nursing students in a health college. Turkish Journal of Clinical Psychiatry, 2018;21:61-7. https://doi.org/10.5505/kpd.2018.65487

3. Yildiz $\mathrm{H}, \mathrm{Kavak} \mathrm{O}$. The regulatory role of compassion in the influence of the personality trait of responsibility on task and contextual performance. Journal of Management, Marketing and Logistics (JMML), 2017;4(4):408-22. https://doi.org/10.17261/Pressacademia.2017.729

4. Silva BRO, Dodson-Lavelle B, Raison CL, Negi LT. Compassion and ethics: Scientific and practical approaches to the cultivation of compassion as a foundation for ethical subjectivity and well-being. Journal of Healthcare, Science and the Humanities, 2012;2(1):14561.

5. Konal E, Ardahan M. (2018). Compassion fatigue and nursing. Health and Community. 2018;28(1):11-6.

6. Gök GA. Unbearable heaviness of compassion: nurses' compassion fatigue. Süleyman Demirel University. The Journal of Faculty of Economics and Administrative Sciences. 2015;20(2):299-313.

7. Yılmaz G, Üstün B. Professional quality of life in nurses: compassion satisfaction and compassion fatigue. J Psychiatric Nurs. 2018;9(3):205-11. https://doi.org/ 10.14744/phd.2018.86648

8. Kelly L, Runge J, Spencer C. Predictors of compassion fatigue and compassion satisfaction in acute care nurses. Journal of Nursing Scholarship. 2015;47(6):522-8. https://doi.org/10.1111/jnu.12162 PMid:26287741

9. Merk T. Compassion fatigue, compassion satisfaction \& burnout among pediatric nurses. Air Medical Journal. 2018;37:291-8. https://doi.org/10.1016/j.amj.2018.07.020

10. Harris C, Griffin MT. Nursing on empty: compassion fatigue signs, symptoms, and system interventions. Journal of Christian Nursing. 2015;32(2):80-7. https://doi.org/10.1097 /CNJ.0000000000000155 PMid:25898441

11. Ruiz-Fernandez MD, Pérez-García E, Ortega-Galán AM. Quality of life in nursing professionals: burnout, fatigue, and compassion satisfaction. Int J Environ Res Public Health. 2020;17:1253. https://doi.org/10.3390/ijerph 17041253

12. Dikmen Y, Aydın Y. Compassıon fatigue in nurses: What? How? What To Do? J Hum Rhythm. 2016;2(1):13-21.

13. Peters E. Compassion fatigue in nursing: A concept analysis. Nurs Forum. 2018;53(4):466-80. https://doi.org/10.1111/nuf.12274 PMid:29962010

14. Şirin M, Yurttaş A. Cost of nursing care: compassion fatigue. Dokuz Eylul University E-Journal of Nursing Faculty. 2015;8(2):123-30.

15. Lachman VD. Compassion fatigue as a threat to ethical practice: Identification, personal and workplace prevention/management strategies. MEDSURG Nursing. 2016;25(4):275-8.
16. Filizöz F, Aşçı A, Mesci G, Bağcivan E. Nurses' ethical sensitivity: research on central public hospitals in Sivas province. Turkish Journal of Business Ethics. 2015;8(1):4766. https://doi.org/10.12711/tjbe.2015.8.1.0144

17. Dalcalı BK, Şendir M. Determining the relationship between nurses personal values and their ethical sensitivity. Florence Nightingale Journal of Nursing. 2016;24(1):1-9.

18. Kahriman i, Calık KY. Ethical sensitivity of clinical nurses. Gümüşhane University Journal of Health Science. 2017;6(3):111-21.

19. Basak T, Uzun Ş, Arslan F. Investigation of the moral sensibility of intensive care nurses. Gülhane Medical Journal. 2010;52(2):76-81.

20. Leget $\mathrm{C}$, Olthuis $\mathrm{G}$. Compassion as a basis for ethics in medical education. J Med Ethics. 2007;33:617-20. https://doi.org/10.1136/jme.2006.017772 PMid:17906063 PMCid:PMC2652803

21. Polat FN, Erdem R. The relationship between the level of compassion fatigue and quality of professional life: the case of medical professionals. Journal of Suleyman Demirel University Institute of Social Sciences. 2017;26(1):291-312.

22. Pommier EA. The compassion scale. Dissertation Abstracts International Section A: Humanities and Social Sciences. 2011;72(4-A):1174.

23. Akdeniz S, Deniz ME. The Turkish adaptation of Compassion Scale: The validity and reliability study. The Journal of Happiness \& Well-Being. 2016;4(1):50-61.

24. Tosun H. Moral Sensitivity Questionnaire (MSQ): Turkish adaptation of the validity and reliability. J Contemp Med. 2018;8(4):316-21. https://doi.org/10.16899/gopctd.467052

25. Çınar F, Aslan FE. Measuring compassion level of operating room nurses: a turkish validity and reliability research. Kocaeli Med J. 2018;7(3):222-9. https://doi.org/10.5505/ ktd.2018.78942

26. Ledoux K. Understanding compassion fatigue: understanding compassion. Journal of Advanced Nursing. 2015;71(9):2041-50. https://doi.org/10.1111/jan.12686 PMid:25981240

27. Duarte J, Pinto-Gouveia J, Cruz B. Relationships between nurses' empathy, self-compassion and dimensions of professional quality of life: A cross-sectional study. Int J Nurs Stud. 2016;60:1-11. https://doi.org/10.1016/ j.ijnurstu.2016.02.015 PMid:27297364

28. Kawar LN, Radovich P, Valdez RM, Zuniga S, Rondinelli J. Compassion fatigue and compassion satisfaction among multisite multisystem nurses. Nurs Adm Q. 2019;43(4):35869. https://doi.org/10.1097/NAQ.0000000000000370 PMid: 31479058

29. Zhang YY, Han WL, Qin W, Yin HX, Zhang CF, Kong C, et al. Extent of compassion satisfaction, compassion fatigue and burnout in nursing: A meta-analysis. J Nurs Manag. 2018;26(7):810-9. https://doi.org/10.1111/jonm.12589 PMid:30129106

30. Hooper C, Craig J, Janvrin DR, Wetsel MA, Reimels E. Compassion satisfaction, burnout, and compassion fatigue among emergency nurses compared with nurses in other selected inpatient specialties. J Emerg Nurs. 2010;36(5):420-7. https://doi.org/10.1016/j.jen.2009.11.027 PMid:20837210

31. Sacco TL, Ciurzynski SM, Harvey ME, Ingersoll GL. Compassion satisfaction and compassion fatigue among critical care nurses. Critical Care Nurse. 2015;35(4):32-44. https://doi.org/10.4037/ccn2015392 PMid:26232800 
32. Aksu T, Akyol A. Investigation of the moral sensibility of nurses in İzmir. Turkiye Klinikleri Journal of Medical EthicsLaw and History. 2011;19(1):16-24.

33. Ertuğ N, Aktaş D, Faydali S, Yalçın O. Ethical sensitivity and related factors of nurses working in the hospital settings. Acta Bioethica. 2014;20(2):265-70. https://doi.org/10.4067/ S1726-569X2014000200014

34. Dikmen Y. Investigation of ethical sensitivity in intensive care nurses. Cumhuriyet Nursing Journal. 2013;2(1):1-7.

35. Öztürk H, Hintistan S, Kasım S, Candaş B. Ethical sensitivity of physicians and nurses in intensive care units. Journal of Intensive Care Nursing. 2009;13(2):77-84.

36. Tazegün A, Çelebioğlu A. Ethical sensitivity levels of pediatric nurses and effective factors. Journal of Behçet Uz Children's Hospital. 2016;6(2):97-102. https://doi.org/ 10.5222/buchd.2016.097
37. Yılmaz D, Düzgün F, Uzelli Yılmaz D, Korhan EA, Dikmen Y. Examination of ethical sensitivity and related factors of nurses in internal clinics: an example of university hospital. Dokuz Eylul University E-Journal of Nursing Faculty. 2018;11(2):157-63.

38. Saleh ZN, Loghmani L, Rasouli M, Nasiri M, Borhan F. Moral distress and compassion fatigue in nurses of neonatal intensive care unit. Electron J Gen Med. 2019;16(2):em116. https://doi.org/10.29333/ejgm/93473

39. Maiden J, Georges JM, Connelly CD. Moral distress, compassion fatigue and perceptions about medication errors in certified critical care nurses. Dimensions of Critical Care Nursing. 2011;30(6):339-45. https://doi.org/10.1097/ DCC.0b013e31822fab2a PMid:21983510 